\title{
Spraying of Leaf-Colonizing Bacillus amyloliquefaciens Protects Pepper from Cucumber mosaic virus
}

Ga Hyung Lee, Molecular Phytobacteriology Laboratory, Super-Bacteria Research Center, KRIBB, Daejeon 305-806, South Korea; and Choong-Min Ryu, Molecular Phytobacteriology Laboratory, Super-Bacteria Research Center, KRIBB, Daejeon 305-806, South Korea, and Biosystems and Bioengineering Program, University of Science and Technology, Daejeon 305-350, South Korea

\begin{abstract}
Lee, G. H., and Ryu, C.-M. 2016. Spraying of leaf-colonizing Bacillus amyloliquefaciens protects pepper from Cucumber mosaic virus. Plant Dis. 100:2099-2105.
\end{abstract}

Beneficial plant-associated bacteria protect host plants against pathogens, including viruses. However, leaf-associated (phyllosphere) bacteria have rarely been investigated as potential triggers of plant systemic defense against plant viruses. We found that leaf-colonizing Bacillus amyloliquefaciens strain 5B6 (isolated from a cherry tree leaf) protected Nicotiana benthamiana and pepper plants against Cucumber mosaic virus (CMV). In a field trial, treatment with strain 5B6 significantly reduced the relative contents of CMV coat protein RNA compared with the water control over a 3 -year period, as revealed by quantitative reverse-transcription polymerase chain reaction. The expression of Capsicum annuum pathogenesis-related
(PR) genes $C a P R 4, C a P R 5$, and $C a P R 10$ was upregulated in field-grown pepper plants treated with strain 5B6. In addition, the accumulation of two naturally occurring viruses, Broad bean wilt virus and Pepper mottle virus, was reduced by foliar treatment with strain $5 \mathrm{~B} 6$, which is similar to the results for benzothiadiazole treatment as a positive control. Taken together, the results suggest that strain 5B6 has strong potential for protecting plants against viruses by increasing defense priming of salicylic acid and jasmonic acid signaling in pepper under field conditions. This is the first report of the protection of a plant against viral diseases by foliar application of leafassociated bacilli.
Plant diseases are a critical problem for cultivated crop plants, causing serious yield loss and resulting in increased labor, cost, and health issues caused by the application of harmful chemicals (Lamberth et al. 2013). Among the many plant diseases, viral diseases cause the most serious problems once they occur in the field because virus control methods are currently unavailable (Mandadi and Scholthof 2013; Scholthof et al. 1993). To date, practical control measures include monitoring and chemical control of the vector causing the viral disease to reduce yield losses (Perring et al. 1999). In addition, viral resistance breeding and transformationbased genetic engineering are the most widely used methods for controlling viral diseases. However, the use of these techniques is limited due to the long time required for crossing in the field and environmental safety issues in many countries (Agrios 2005). In addition to conventional breeding and foreign gene transformation methods, the use of inducible defense mechanisms against viruses has been shown to be effective in many plant species (Murphy 2006). In 1960 and 1961, Yarwood and Ross separately discovered the inducible form of plant resistance against viruses by a localized virus or weak virulent strain of virus, referred to as systemic acquired resistance (SAR) (Ross 1961; Yarwood 1960). Much effort has subsequently focused on inducing SAR against diverse viruses (Kessmann et al. 1994; Murphy et al. 1999; Pennazio and Roggero 1998; Singh et al. 2004; van Loon et al. 1998). Initially, the application of SAR to manage viral diseases was recognized as a promising tool, but it was later found to be limited due to the laborious process of woundmediated viral inoculation on individual plants and the low infection rates.

To overcome the limitations of virus-elicited SAR against the same and other pathogenic viruses, pathogenic and saprophytic bacteria have been used as elicitors for inducing SAR against Cucumber mosaic virus (CMV) and Tobacco mosaic virus (TMV) in cucumber and tobacco (Bergstrom et al. 1982; Loebenstein 1966; Mann 1969).

Corresponding author: C.-M. Ryu; E-mail: cmryu @kribb.re.kr

Accepted for publication 20 May 2016.

http://dx.doi.org/10.1094/PDIS-03-16-0314-RE

(C) 2016 The American Phytopathological Society
In the late 1990s, a group of root-associated nonpathogenic bacteria referred to as plant-growth-promoting rhizobacteria (PGPR) were reported as a new class of elicitors against viruses in a process referred to as induced systemic resistance (ISR) (Maurhofer et al. 1994; Raupach and Kloepper 1998; Raupach et al. 1996). Treating seed and seedlings with the selected PGPR strains reduces the incidence of viral diseases (De Meyer et al. 1999; Maurhofer et al. 1994; Raupach et al. 1996). For instance, the drench application of Pseudomonas fluorescens CHA0 and treatment of seed with $P$. putida $89 \mathrm{~B} 61$ and Serratia macerans 90-166 reduces the number of Tobacco necrosis virus-mediated local lesions in tobacco and delays symptom development caused by CMV in cucumber and tomato under greenhouse conditions (Maurhofer et al. 1994; Raupach et al. 1996; Zehnder et al. 2000). This process was attempted to treat field-grown cucumber against CMV and tomato against Tomato mottle virus (ToMoV) (Murphy et al. 2000; Zehnder et al. 2000). Intriguingly, the disease incidence and accumulation of ToMoV were significantly reduced via the application of selected PGPR on seed, and the number of insect vectors (whitefly) showed a similar pattern. The protection by PGPR was maintained up to 40 days after transfer to the field. These findings point to the potential to develop a commercial biopreparation to manage viral diseases (Song et al. 2013). Furthermore, the commercial formulation of two PGPR mixtures also led to successful protection of tomato against CMV (Murphy et al. 2003).

Diverse aspects of the mechanisms underlying protection against viruses by SAR and ISR have been uncovered based on our understanding of plant defense signaling and searches for bacterial determinants (van Loon et al. 1998). The best-understood defense signaling mechanism conferring virus resistance is salicylic acid (SA) signaling (Murphy et al. 1999). Exogenous application of SA and its derivatives produces similar inducible resistance responses to viral infection (Singh et al. 2004). In contrast to a previous study, an experiment investigating bacterial determinants of PGPR revealed that SA is not a metabolite that elicits ISR (van Loon et al. 1998). Mutants of $P$. fluorescens CHA0 and $S$. macerans 90-166 deficient in SA production showed similar levels of plant protection to the virus compared with the wild type, indicating that ISR induction functions in an SA-independent manner (Maurhofer et al. 1994; Press et al. 2001). Recently, pepper seedlings subjected to drench application of bacterial volatile compounds and their derivatives showed reduced symptom development and viral accumulation caused by CMV (Choi et al. 2014; Song et al. 2013). 
In many cases, in the greenhouse and field, chemical control methods such as benzothiadiazole (BTH) and jasmonic acid (JA) treatment often display a significant growth penalty referred to as the allocation fitness cost while eliciting greater plant systemic resistance (Heil and Baldwin 2002). To overcome this problem, the effect of PGPR-mediated ISR on plant growth and induction of systemic resistance, particularly against viruses, has been investigated (Maurhofer et al. 1994; Raupach and Kloepper 1998; Raupach et al. 1996). PGPR application to plants produces inconsistent results when applied in the field (Kloepper et al. 2004). This inconsistency in control efficiency is a pitfall of this technique when PGPR is applied to the roots and seed due to different root colonization capacities. In addition, signal transduction from belowground to aboveground plant parts when the virus is transmitted into the plant cell leads to inconsistent results when the beneficial effects of PGPR are introduced. Nonetheless, in these field and greenhouse trials, bacteria and their byproducts exhibited the potential to control viral diseases without reducing plant growth (Song et al. 2013).

In the current study, we evaluated the potential use of foliar application of leaf-inhabiting bacteria for managing CMV, a common and economically important viral disease of pepper in South Korea, under greenhouse and field conditions. Strain 5B6, which was isolated from a cherry tree leaf and identified as Bacillus amyloliquefaciens, was used as a model system, because it is a stable leaf colonizer and a strong ISR elicitor against Xanthomonas axonopodis pv. vesicatoria in pepper (Chung and Ryu 2016). In the field trials, fewer symptoms such as mosaic, shoe-string appearance, and deformation of leaves caused by virus were observed after prespray application of strain 5B6 suspension compared with the control. The symptoms, which are characteristic of infection by CMV, were confirmed by quantitative reverse-transcription polymerase chain reaction (qRT-PCR) with CMV coat protein (CP)-specific primers. We initially assessed the ISR capacity of strain 5B6 in Nicotiana benthamiana and applied the results to pepper plants in the greenhouse and in 3-year field experiments. The elicitation of ISR in the field was validated by examining the expression of molecular markers of induced resistance, including Capsicum annuum pathogenesis-related (PR) genes CaPR4, $C a P R 5$, and CaPR10. In addition to controlling CMV infection, foliar spraying of strain 5B6 also attenuated the severity of diseases caused by naturally occurring plant viruses such as Broad bean wilt virus and Pepper mottle virus (PepMoV) in the field. This is the first report of the use of a leaf-colonizing bacillus to elicit induced resistance against CMV in pepper by foliar application.

\section{Materials and Methods}

Bacteria preparation. The model bacterium used was B. amyloliquefaciens 5B6, isolated from a cherry tree leaf (Kim et al. 2012). Prior to use, B. amyloliquefaciens 5B6 and FZB42 that was generated a spontaneous rifampicin-resistant strain was stored at $-70^{\circ} \mathrm{C}$ in tryptic soy broth (TSB) agar medium (TSA; Difco Co.) containing 20\% glycerol. The strains were removed from ultracold storage, streaked onto TSA plates that contained rifampicin at $100 \mu \mathrm{g} / \mathrm{ml}$, and incubated at $30^{\circ} \mathrm{C}$ for $24 \mathrm{~h}$ to check for purity. Single colonies were transferred onto TSA plates that contained rifampicin at $100 \mu \mathrm{g} / \mathrm{ml}$ and incubated for 2 days. Fully grown bacteria were scraped off the plates and resuspended in sterilized distilled water (SDW). Based on the optical densities, the bacterial suspensions were adjusted to $10^{8} \mathrm{CFU} / \mathrm{ml}$ (optical density at $600 \mathrm{~nm}\left[\mathrm{OD}_{600}\right]=1$ ).

Leaf colonization assay. To assess the leaf colonization capacity of B. amyloliquefaciens 5B6 and FZB42, which were isolated from plant leaves and roots, respectively, the fully expanded leaves of 4-week-old pepper plants were treated with $10 \mathrm{ml}$ of bacterial suspension at $\mathrm{OD}_{600}=1$ by spray application until run-off. The three leaf samples were collected on day 0 and 7 and macerated in a homogenizer (Perkin-Elmer) in $1 \mathrm{ml}$ of sterile distilled water. Dilution plating was performed 2 to 3 days after plating to determine the number of CFU on TSB medium containing rifampicin at $100 \mu \mathrm{g} / \mathrm{ml}$.

Pepper and $N$. benthamiana growth chamber experiments. Pepper ( $C$. annuum L. 'Bukwang') and $N$. benthamiana plants were cultivated in a growth chamber. Application of chemical treatments to elicit induced resistance in pepper was performed as previously described (Kang et al. 2007; Song et al. 2013). Briefly, seeds of pepper and $N$. benthamiana were surface sterilized with $6 \%$ sodium hypochlorite, washed four times with SDW, and sown on autoclaved soilless potting medium (Punong Co. Ltd., Gyeonnju, S. Korea). Pepper and $N$. benthamiana plants were cultivated in a growth chamber at $25^{\circ} \mathrm{C}$ under a photocycle consisting of $16 \mathrm{~h}$ of light and $8 \mathrm{~h}$ of darkness. Five leaves from each plant ( 3 weeks old) were sprayed with $30 \mathrm{ml}$ of $0.5 \mathrm{mM}$ BTH (benzo(1,2,3)thiadiazole-7-carbothioic acid S-methyl ester; provided by Syngenta Korea), $30 \mathrm{ml}$ of a bacterial suspension of strain $5 \mathrm{~B} 6$ at $\mathrm{OD}_{600}=1$, and $30 \mathrm{ml}$ of sterilized water (control) using a handy sprayer (SPL Life Science). Other chemicals were purchased from Sigma-Aldrich Co.

Virus inoculation. Four-week-old pepper plants were used to validate CMV infection under field conditions. Three of the first four leaves were rub inoculated with CMV 7 days after spray inoculation of strain 5B6 at $\mathrm{OD}_{600}=1$, as described previously (Song et al. 2013). The Fny strain of CMV was obtained from the Plant Virus GenBank (http://knrrb.knrrc.or.kr/index.jsp?rrb=pvgb). Virus quantification was performed via qRT-PCR as described below at 2 weeks after virus inoculation.

Pepper field trials. To evaluate induced resistance against naturally occurring viruses, field experiments were performed in 2013, 2014, and 2015 at Geumsan-gun, Chungcheongnam-do, South Korea $\left(36^{\circ} 35^{\prime} 32.27^{\prime \prime}\right.$ North, $127^{\circ} 30^{\prime} 34.75^{\prime \prime}$ East). Single-row treatment plots consisted of 20 plants and were replicated four times in a completely randomized design. One month after transplanting, the foliar parts of 20 pepper seedlings were sprayed with 5 liters of the bacterial suspension at $\mathrm{OD}_{600}=1$. The same volume of $1 \mathrm{mM}$ BTH and water were used as positive and negative controls, respectively. The row size for each treatment was 50 by 800 by $20 \mathrm{~cm}$. In all, 8 of 20 plants per replicate were randomly selected for assessment of disease. The disease severity of viral symptoms caused by naturally occurring diverse viruses was measured at 120 and 125 days posttransplantation in 2014 and 2015, respectively. Severity of naturally occurring viral disease was assessed on a 0-to-5 scale as follows: $0=$ no symptoms; $1=$ mild deformation and mosaic of the youngest two leaves; 2 = pronounced leaf deformation and mosaic of the youngest two leaves, with progression of symptoms into sequentially older leaves; 3 = pronounced leaf deformation and mosaic progression beyond the two youngest leaves, with all leaves expressing some form of virus-induced symptoms; $4=$ similar symptoms as described for a rating of 3 , with plants also being stunted in growth (where stunting includes both reduced internode extension and smaller leaves); and $5=$ severe stunting, with the majority of leaves being small, severely deformed, and tightly bunched together (Choi et al. 2014; Song et al. 2013).

Yield measurements. To measure fruit yield, the pepper fruit from 20 plants in a row were harvested and weighed at 16 weeks after transplanting, with four replications.

qRT-PCR to investigate virus accumulation and defense gene expression. qRT-PCR was performed using a Bio-Rad CFX96 instrument. Total RNA was isolated from pepper leaf tissues using Tri reagent (Molecular Research Inc.) according to the manufacturer's instructions and as described in our previous reports (Choi et al. 2014; Lee et al. 2012). First-strand cDNA synthesis was performed with $2 \mu \mathrm{g}$ of DNase-treated total RNA, oligo-dT primers, and Moloney murine leukemia virus reverse transcription (Enzynomics). The qRT-PCR mixtures included cDNA, iQ SYBR Green Supermix (Bio-Rad Inc.), and $10 \mathrm{pM}$ each primer. The cycling parameters consisted of initial polymerase activation of $10 \mathrm{~min}$ at $95^{\circ} \mathrm{C}$ and 40 cycles of $30 \mathrm{~s}$ at $95^{\circ} \mathrm{C}, 60 \mathrm{~s}$ at $55^{\circ} \mathrm{C}$, and $30 \mathrm{~s}$ at $72^{\circ} \mathrm{C}$. Conditions were determined by comparing threshold values in a dilution series of the RT product with those of a non-RT template control and a nontemplate control for each primer pair.

For viral diagnosis, test samples were selected from areas of the plant that exhibited disease symptoms in the field. The pool of four plants per replicate (three leaves per plant) was prepared for qRTPCR analysis. Four replications were used for data analysis. Samples were ground in $50 \mathrm{mM} \mathrm{NaHPO}_{4}$ (pH 7.0) buffer. To confirm virus 
infection, qRT-PCR was performed using specific primers for CMV CP (5'-CGTTGCCGCTATCTCTGCTAT-3', forward and 5'-GGA TGCTGCATACTGACAAACC-3', reverse), Broad bean wilt virus (BBWV; (5'-AATGAAGTGGTGCTCAACTACACA-3', forward and $5^{\prime}$-TTTTGGAGCATTCAACCATTTGGA-3', reverse), PepMoV

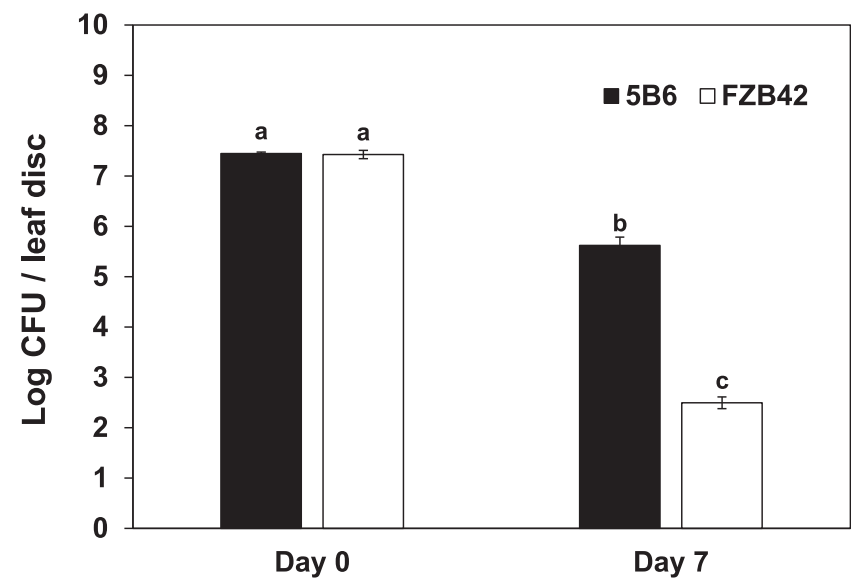

Fig. 1. Comparison of population dynamics between leaf-associated Bacillus amyloliquefaciens 5B6 and root-associated B. amyloliquefaciens FZB42. The number of bacteria was measured at 0 and 7 days after foliar application of $B$. amyloliquefaciens strains $5 \mathrm{~B} 6$ and FZB42 at an optical density at $600 \mathrm{~nm}=1$ on leaves of 4-weekold pepper seedlings. Bacteria developed spontaneous resistance to rifampicin at $100 \mu \mathrm{g} / \mathrm{ml}$. Sample size: $n=8$ plants per treatment. Different letters indicate significant differences between two bacterial treatments according to least significant difference at a significance level of $P=0.05$.

A

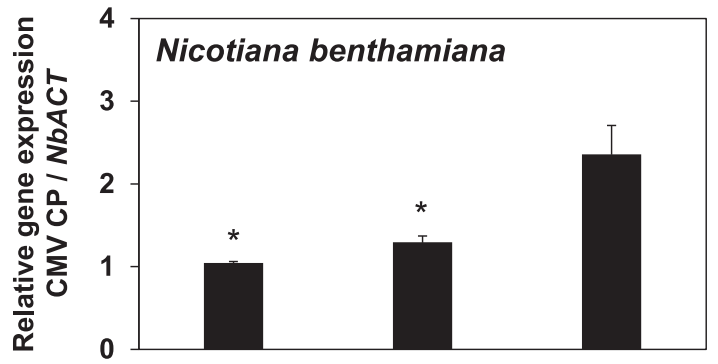

B

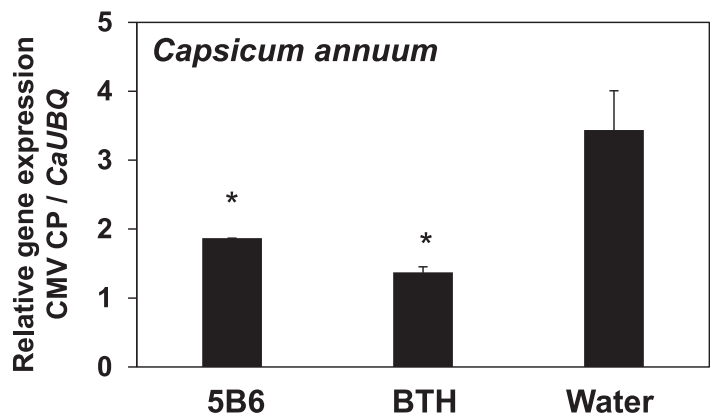

Fig. 2. Effects of Bacillus amyloliquefaciens $5 \mathrm{~B} 6$ on protection of A, Nicotiana benthamiana and B, Capsicum annuum against Cucumber mosaic virus (CMV) via foliar application in the greenhouse. CMV was rub inoculated onto 6-week-old $N$. benthamiana plants and 3-week-old Capsicum annuum plants 1 week after strain $5 \mathrm{~B} 6$ treatment. The results of quantitative reverse-transcription polymerase chain reaction (qRT-PCR) show a reduction of CMV coat protein (CP) RNA expression by strain $5 \mathrm{~B} 6$ treatment at 2 weeks after virus challenge; $1 \mathrm{mM}$ benzothiadiazole (BTH) and water treatments were used as the positive and negative controls, respectively. Housekeeping genes $N b A C T$ and $C a U B Q$ were used for normalization of $\mathrm{CP}$ expression in N. benthamiana and $\mathrm{C}$. annuum, respectively. Analysis of virus accumulation by qRT-PCR was conducted at 50 days postinoculation of virus in plants treated with $5 \mathrm{~B} 6$ and $0.5 \mathrm{mM} \mathrm{BTH}$. Error bars represent means \pm standard error of the mean. Sample size: $n=8$ plants per treatment. Asterisks above bars indicate significant differences between bacteria and chemical treatments and control according to least significant difference at a significance level of $P=0.05$.
(5'-AAGATCAGACACATGGA-3', forward and 5'-CAAGCAAGG GTATGCATGT- $3^{\prime}$, reverse), and Pepper mild mottle virus (PMMoV; 5'-ACAGTTTCCAGTGCCAATCA-3', forward and 5'-AAGCGTC TCGGCAGTTG-3', reverse).

The expression of candidate priming genes was analyzed using the following primer pairs: 5'-AACTGGGATTTGAGAACTGCCAGC-3' (CaPR4-F) and 5'-ATCCAAGGTACATATAGAGCTTCC-3' (CaPR4-R), 5'-CTCCACAAGAAACAAGGCA-3' (CaPR5-F) and 5'-GTACG AAGCACGCACACAA-3' (CaPR5-R), and 5'-GCACGGCAATCA TCTTATCCTA-3' (CaPR10-F) and 5'-GTTCTTTCCATGACAA CCAATTG-3' (CaPR10-R). CaUBQ (ubiquitin) was analyzed using the primers 5'-GCACAAGCACAAGAAGGTTAAG-3' (forward) and $5^{\prime}$-GCACCACACTCAGCATTAGGA-3' (reverse) as a loading control to ensure that equal amounts of RNA were used in each assay. Relative transcript quantification was performed using the $2^{-\Delta \Delta \mathrm{CT}}$ method. Standard error of mean values among replicates was calculated
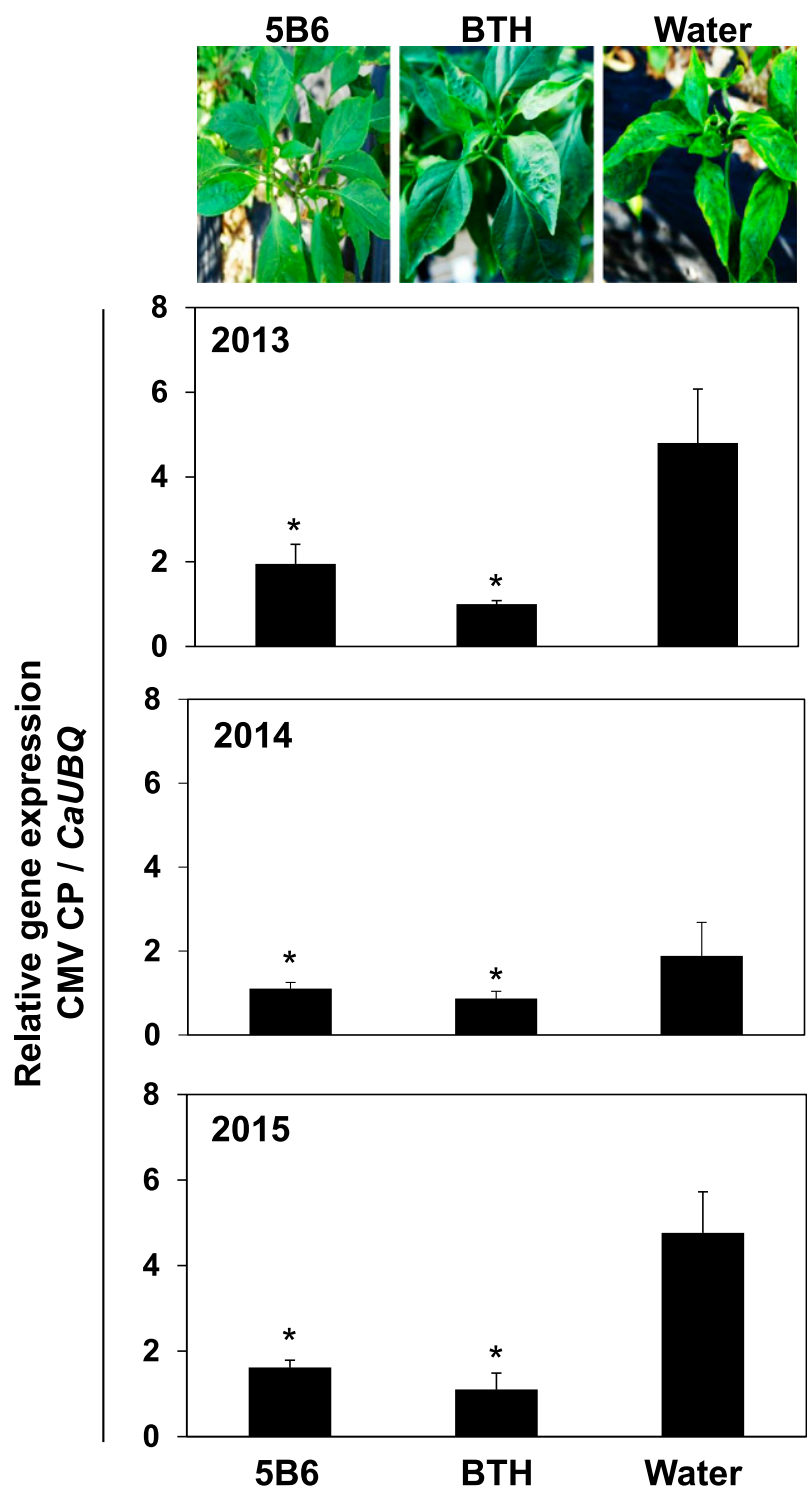

Fig. 3. Field trials examining the effectiveness of strain $5 \mathrm{~B} 6$ treatment on plant protection against Cucumber mosaic virus (CMV) by foliar application. Pepper seedlings were treated three times with Bacillus amyloliquefaciens $5 \mathrm{~B} 6$ suspension at an optical density at $600 \mathrm{~nm}=1$ before transplanting. Results of quantitative reverse-transcription polymerase chain reaction show a reduction in CMV coat protein (CP) RNA expression after treatment with $5 B 6$ and $1 \mathrm{mM}$ benzothiadiazole (BTH) at 40 days post transplantation. The housekeeping gene CaUBQ was used for normalization. Error bars represent means \pm standard error of the mean. Sample size: $n=15$ plants per treatment. Asterisks above bars indicate significant differences between bacteria and chemical treatments and the control according to least significant difference at a significance level of $P=0.05$. 
using Bio-Rad manager (version 2.1; Bio-Rad CFX Connect). Student's $t$ test was used to determine statistically significant differences between treated and untreated samples. If $P$ values were $<0.05$, the target gene was considered to be differentially expressed. Relative transcript abundance was normalized with respect to $C a U B Q$ mRNA levels.

Statistical analysis. Data were assessed using analysis of variance (ANOVA) tests with JMP software version 4.0 (SAS Institute Inc.; http://www.jmp.com/en_us/software.html). The significance of the effects of chemical treatments was determined based on the magnitude of the $F$ value at $P \leq 0.05$. When a significant $F$ value was obtained for treatments, separation of means was accomplished using Fisher's protected least significant difference test at $P \leq 0.05$. Replicated trials had similar outcomes, and one representative trial per experiment is reported.

\section{Results}

Niche colonization of strains 5B6 and FZB42. In our previous study (Chung and Ryu 2016), we identified more than 30 leafassociated bacterial strains and evaluated their capacity for leaf colonization and their enzyme activities. To determine the niche colonization capacity of strain 5B6, which was isolated from cherry tree leaves, we assessed the decline in leaf colonization at 0 and 7 days after treatment compared with strain FZB42; this strain was isolated from plant roots and is the same species and a genetically close taxon to strain 5B6, which we determined by total genome comparison and isolation of the strains from soil (Fig. 1). Intriguingly, the number (CFU) of strain 5B6 cells on the leaf declined by $2.2 \times 10^{5}$, while the CFU of strain FZB42 was $2.4 \times 10^{2}$ at 7 days after spray application. The initial populations of the two bacterial treatment groups were similar (Fig. 1).

Screening of leaf-associated bacteria-mediated plant protection against CMV by foliar spraying of bacterial suspension. We evaluated the capacity of strain 5B6 to reduce the severity of viral symptoms and contents in the model plant $N$. benthamiana. Preapplication of bacterial suspension resulted in a 2.25 -fold reduction in viral gene expression compared with the water control. The results were similar for the positive control (BTH treatment; (Fig. 2A). Next, we assessed the use of this strain to protect the crop plant pepper against CMV under greenhouse conditions. The viral content, as quantified qRT-PCR based on the ratio of CMV CP gene expression to $C a U B Q$, was 1.87 and 1.37 for $5 \mathrm{~B} 6$ and $\mathrm{BTH}$ treatments, respectively, whereas it was 3.43 for the water control (Fig. 2B). These results indicate that foliar inoculation with strain 5B6 successfully protects pepper seedlings against CMV infection.

Evaluation of strain 5B6-mediated protection against CMV under field conditions. We then investigated the effectiveness of

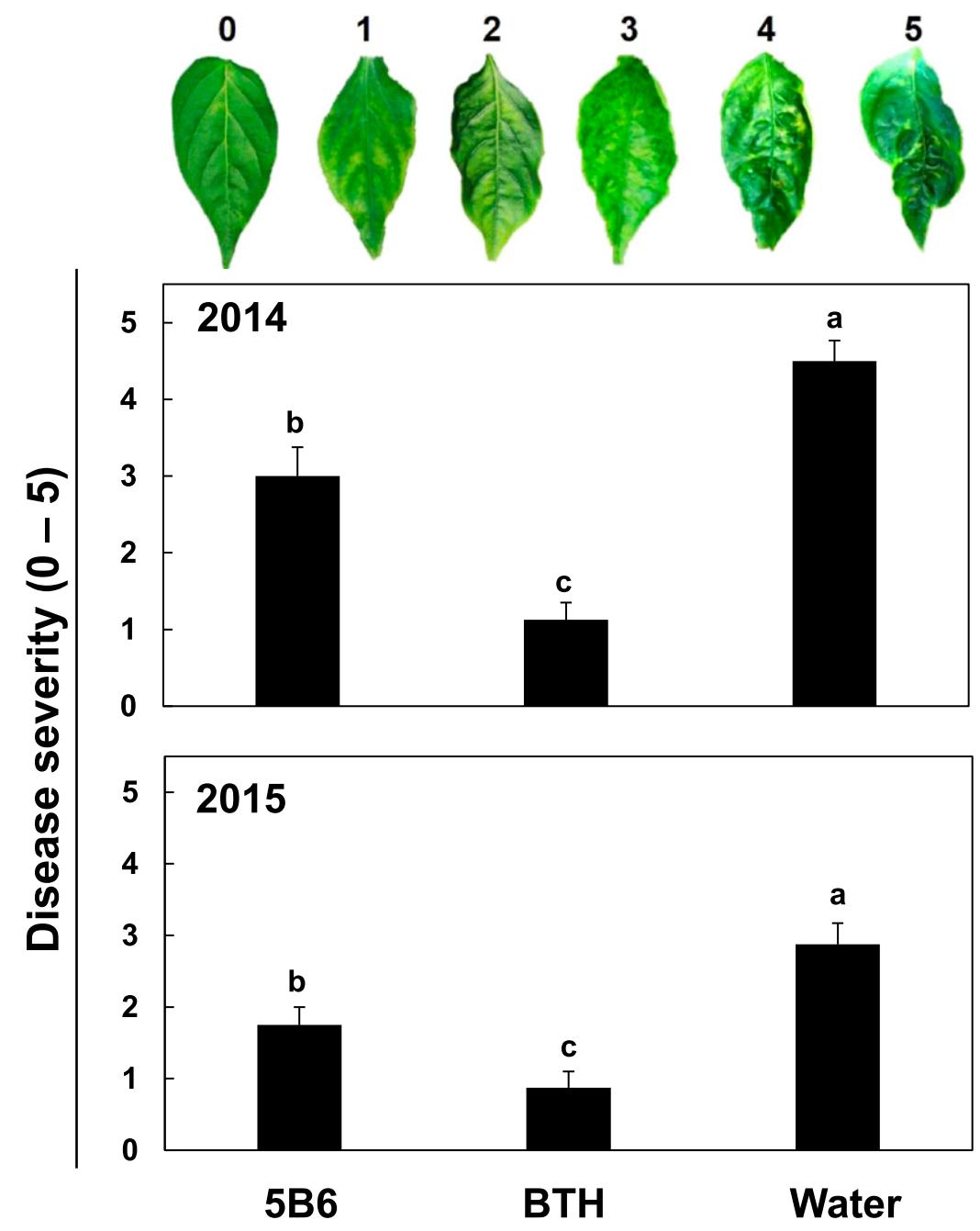

Fig. 4. Suppression of viral disease severity by foliar spray of Bacillus amyloliquefaciens $5 \mathrm{~B} 6$ under field conditions. Disease symptoms caused by naturally occurring diverse viruses were evaluated at 120 and 125 days posttransplantation in 2014 and 2015, respectively. Typical viral symptoms were evaluated based on a 0 -to-5 disease severity scale, where $0=$ no symptoms; 1 = mild deformation and mosaic of the youngest two leaves; 2 = pronounced leaf deformation and mosaic of the youngest two leaves, with progression of symptoms into sequentially older leaves; 3 = pronounced leaf deformation and mosaic progression beyond the two youngest leaves, with all leaves expressing some form of virus-induced symptoms; 4 = similar symptoms as described for a rating of 3 , with plants also being stunted in growth (where stunting includes both reduced internode extension and smaller leaves); and $5=$ severe stunting, with the majority of leaves being small, severely deformed, and tightly bunched together. Different letters indicate significant differences between treatments $(P<0.05$, least significant difference). Error bars represent means \pm standard error of the mean. Sample size: four replication per treatment ( $n=8$ plants per replication). 
strain 5B6 against CMV in the field. Three-year field trials demonstrated a significant reduction in CMV CP contents and disease severity following foliar application of strain 5B6, with reductions of 2.46-fold in 2013, 1.71-fold in 2014, and 2.95-fold in 2015 compared with the water control (Fig. 3). The levels of reduction were not statistically different from those induced by BTH treatment (Fig. 3), suggesting that strain 5B6 has strong potential for use against CMV under both greenhouse and field conditions. In addition, the disease severity was significantly reduced by a foliar spray of strain 5B6 in 2014 and 2015 (Fig. 4). The BTH treatment showed a greater effect on viral symptom development (Fig. 4).

To evaluate the mode of action of strain 5B6-mediated plant protection against CMV, we assessed the expression of defense-related genes, which was used to represent the elicitation of SAR in pepper due to the inability of strain 5B6 to directly counteract multiplication of CMV in plant cells. Because of the difficulty of inoculation and the low infection rates of CMV in the field, we investigated defense priming of three defense-related genes in pepper plants at 0 and $6 \mathrm{~h}$ postinoculation (hpi) with $X$. axonopodis pv. vesicatoria via infiltration of strain 5B6 on systemic leaves. We measured the expression of the following marker genes: CaPR5 for SA signaling; CaPR4 for
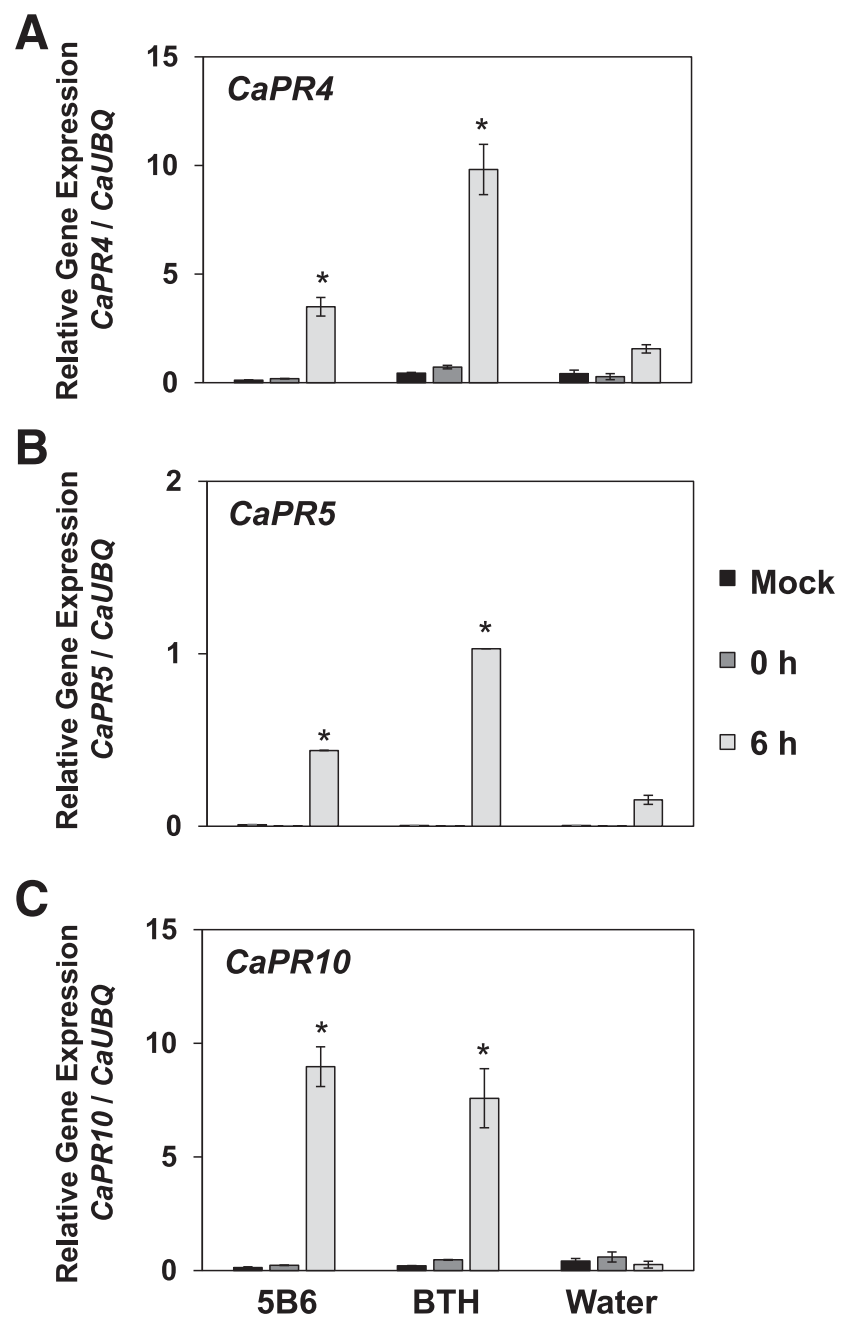

Fig. 5. Induction of defense-related genes in pepper by foliar application of strain 5B6 under field conditions. Quantitative reverse-transcription polymerase chain reaction of $\mathbf{B}$, salicylic acid signaling marker gene CaPR5; A, ethylene markers $\mathrm{CaPR} 4$; and $\mathbf{C}$, jasmonic acid marker gene $\mathrm{CaPR} 10$ in plants treated with $5 \mathrm{~B} 6,1 \mathrm{mM}$ benzothiadiazole $(\mathrm{BTH})$, and water. Samples were taken at 0 and $6 \mathrm{~h}$ after inoculation with Xanthomonas axonopodis pv. vesicatoria. The housekeeping gene $\mathrm{CaUBQ}$ was used for normalization. Asterisks indicate significant differences between chemical and control treatments according to least significant difference at a significance level of $P=0.05$. Error bars represent means \pm standard error of the mean. Sample size: $n=15$ plants per treatment in 2014.
SA and ethylene signaling; and CaPR10 for TMV-inducible, SA, and JA signaling (Fig. 5). CaPR4 and CaPR5 expression was 2.23and 2.66-fold higher, respectively, in strain 5B6-treated plants than in control plants 6 hpi (Fig. 5A and 5B), and CaPRlO expression was significantly $(P=0.05)$ upregulated (as much as 34.46 -fold) in 5B6-treated plants compared with control plants at all time points (Fig. 5C). BTH treatment led to a 6.28-, 6.8-, and 29.1-fold increase in CaPR4, CaPR5, and CaPR10 expression, respectively, at 6 dpi compared with the control. Taken together, these results indicate that strain 5B6 elicited SAR marker gene expression in pepper and that it may be involved in the induction of three defense hormones: SA, ethylene, and JA (Fig. 5).

Effect of strain 5B6 on plant protection against naturally occurring viruses and fruit yield. In addition to the effect of strain 5B6 on plant protection against CMV, we also evaluated its effects on other plant viruses that naturally occur in the field (Fig. 6). Quantification of PepMoV and PMMoV by qRT-PCR revealed a 13.0and 4.7-fold reduction in CMV CP RNA levels in 5B6-treated plants compared with the control (Fig. 6). The positive control (BTH treatment) elicited similar levels of SAR against PepMoV and PMMoV (Fig. 6). Plant protection against BVWV was not elicited by foliar treatment of strain 5B6 but was elicited by BTH application, indicating the ISR capacity of BTH against broad-spectrum viruses. In previous studies, we frequently found that the strong induction of induced resistance caused a yield penalty referred to as the allocation fitness cost (Song et al. 2013; Yang et al. 2011; Yi et al. 2012). Therefore, we examined fruit yield in both 2013 and 2014. The average total weight per pepper plant did not differ between strain 5B6 and the control plants, whereas this value was significantly reduced by BTH treatment in 2013 and 2014 (Table 1). Therefore, no reduction in fruit yield was observed with 5B6 treatment compared with water-treated control plants but BTH treatment consistently and substantially reduced fruit yields in pepper (Table 1).

\section{Discussion}

Initially, strain 5B6 was isolated from a cherry tree and assessed as a biological inducer against $X$. axonopodis pv. vesicatoria, a causal pathogen of bacterial spot disease in pepper (Kim et al. 2012). In the current study, we evaluated the capacity of leaf-colonizing B. amyloliquefaciens strain 5B6 to protect plants against CMV, a notorious plant disease in pepper-growing areas of South Korea that causes serious economic losses yearly. Instead of using the previously described soil application method of PGPR in order to protect plants against viruses, we performed spray application on the aerial parts of the plant with a liquid preparation of strain 5B6, which has been shown to be an efficient technique, even against viruses in the greenhouse. Three-year field trials revealed consistently reduced

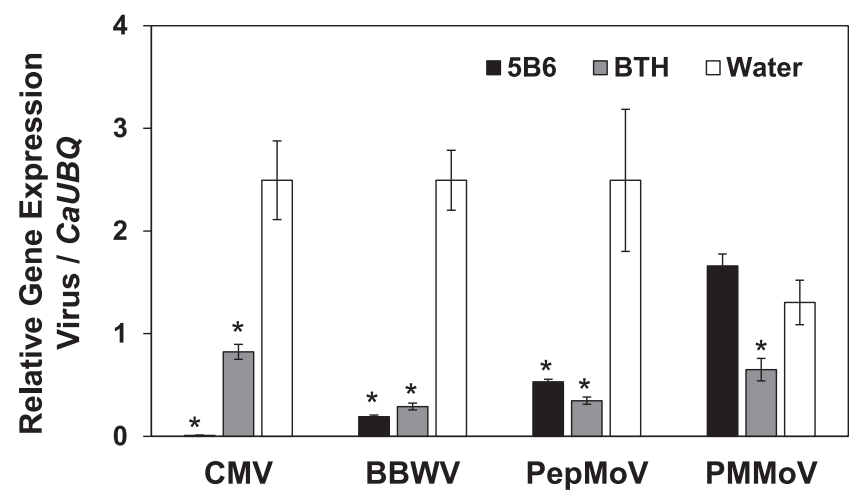

Fig. 6. Evaluation of the effectiveness of strain $5 \mathrm{~B} 6$ on plant protection against naturally occurring viruses by foliar application in the field. Quantification of virusspecific RNA expression caused by naturally occurring target viruses Cucumber mosaic virus (CMV), Broad bean wilt virus (BBWV), Pepper mottle virus (PepMoV), and Pepper mild mottle virus (PMMoV) was performed at 50 days post transplantation. $\mathrm{BTH}=$ benzothiadiazole. Bars represent the mean value \pm standard error of the mean $(n=5)$. The housekeeping gene CaUBQ was used as a control. The experiment was repeated twice with similar results. 
virus accumulation in 5B6-treated plants, as determined by qRTPCR. In addition to ISR against CMV, the titer of naturally occurring BBWV and PepMoV was reduced by prefoliar application of strain $5 \mathrm{~B} 6$, indicating that this technique has strong potential for use as a commercial biopreparation for biological control of viral diseases.

To enable successful foliar application, biological control agents must have strong leaf-colonizing capacity (Mercier and Lindow 2001; Milgroom and Cortesi 2004). Interestingly, the population of strain 5B6 (isolated from the leaf of a cherry tree) on pepper leaf was fairly stable under greenhouse conditions (Fig. 1), whereas the population of strain FZB42 (a model root-colonizing bacterium) sharply decreased at 1 week after inoculation, suggesting that strain 5B6 has specific leaf-colonizing traits. The traits corresponding to leaf colonization have not been characterized, whereas bacterial genes involved in root colonization have been well characterized in Pseudomonas spp. (Dekkers et al. 1998, 2000; Lugtenberg et al. 2001; Mavrodi et al. 2006) and, recently, in Bacillus spp. (Dietel et al. 2013; Kerff et al. 2008; Nihorimbere et al. 2012; Timmusk et al. 2015; Weng et al. 2013).

We demonstrated that foliar application of Bacillus spp. mediated induced resistance against CMV in pepper (Figs. 2, 3, and 4). Foliar application of biological control agents is not a common method compared with soil application (Mercier and Lindow 2001). Bacillus spp. have been intensively evaluated for use as biological control agents because of their long, stable shelf life and consistent effectiveness (Kloepper et al. 2004). The long shelf life of endospore preparations of bacilli has stimulated the development of commercial products consisting of single organisms or a mixture of Bacillus spp. (Kloepper et al. 2004). However, foliar application of Bacillus spp., including B. subtilis and B. cereus, has been investigated to directly inhibit fungal pathogens Wilsonomyces carpophilus on apricot, Botrytis cinerea on chickpea, and Puccinia striiformis f. sp. tritici on wheat (Eşitken et al. 2002; Kishore and Pande 2007; Li et al. 2013). Plant protection by spraying of strain 5B6 only can be explained by elicitation of ISR due to no report on direct inhibition of a plant virus by bacteria or their metabolites.

Diverse means for induced resistance-mediated plant protection against viruses have been introduced (Murphy et al. 2003). Chemical treatments such as SA and BTH have significant benefits in conferring induced resistance against viruses (Tally et al. 1999). For instance, the number of local lesions caused by TMV in tobacco containing the $N$ gene is reduced by pretreatment with acibenzolarS-methyl (Murphy 2006). This SAR response is maintained for 21 days after treatment. More directly, the commercial chemical elicitor BTH successfully attenuates viral symptom development and accumulation in the field (Yi et al. 2012). Even though chemical elicitors are highly effective for managing viral diseases, in many case studies, these chemicals have produced a growth penalty (allocation fitness cost; Heil and Baldwin 2002). In contrast to chemically induced resistance, biologically mediated induced resistance against viruses has been intensively investigated since Ross first demonstrated SAR by TMV (Ross 1961). Induced resistance by pathogenic and even avirulent viruses has not previously been utilized to control viral diseases due to the difficultly in preparing inoculum and inoculating the plant. In the current study, we introduced a leaf-colonizing

Table 1. Effect of Bacillus amyloliquefaciens strain 5B6 on pepper yield under field conditions ${ }^{\mathrm{z}}$

\begin{tabular}{lcrlccc}
\hline & \multicolumn{2}{c}{2013} & & \multicolumn{2}{c}{2014} \\
\cline { 2 - 3 } \cline { 6 - 6 } Treatment & Weight (kg) & Fruit $(\boldsymbol{n})$ & & Weight (kg) & Fruit $(\boldsymbol{n})$ \\
\hline 5B6 & $3.5 \mathrm{a}$ & $128.5 \mathrm{a}$ & & $0.9 \mathrm{a}$ & $45.3 \mathrm{a}$ \\
BTH & $0.9 \mathrm{~b}$ & $26.5 \mathrm{~b}$ & & $0.3 \mathrm{~b}$ & $22.6 \mathrm{~b}$ \\
Water & $2.8 \mathrm{a}$ & $100.1 \mathrm{a}$ & & $0.7 \mathrm{a}$ & $38.0 \mathrm{a}$ \\
\hline
\end{tabular}

${ }^{\mathrm{z}}$ Yield was measured at 4 months after treatment with $5 \mathrm{~B} 6,1 \mathrm{mM}$ benzothiadiazole (BTH), or water (control). Pepper seedlings were transplanted to the field in 2013 and 2014. Different letters for the three treatments on the same assessment day indicate significant differences between treatments $(P=0.05$; least significant difference)
Bacillus amyloliquefaciens strain to manage CMV in pepper by foliar spraying (Figs. 2, 3, and 4). The statistical difference between strain 5B6 and BTH treatments for CMV accumulation (Fig. 3) and disease severity (Fig. 4) indicate that BTH broadly or effectively elicits ISR against diverse viruses in the field. For instance, strain 5B6 did not elicit ISR against PMMoV but BTH did (Fig. 6).

Previously, most experiments focused on controlling viruses were conducted by soil application (Maurhofer et al. 1994; Raupach and Kloepper 1998; Raupach et al. 1996). For example, plants exposed to soil-drenching and seed treatment with bacilli PGPR strains, including B. subtilis and B. pumilus, had lower disease severity at 14 days after virus inoculation, which was maintained until 28 days after inoculation (Jetiyanon et al. 2003; Murphy et al. 2003). Similarly, the soil drench application of strain 5B6 elicited plant systemic resistance (data not shown).

To suppress the spread of plant viruses, at least one of the three major steps (i.e., viral replication, cell-to-cell movement, and systemic movement) must be blocked. However, the exact mode of action of ISR against a virus by foliar application of $B$. amyloliquefaciens 5B6 has not been elucidated, whereas the transcriptional expression of PR genes CaPR4, CaPR5, and CaPR10 was examined (Fig. 5). The expression patterns of CaPR4 (encoding a putative antifungal protein) and $C a P R 5$ (encoding an osmotin-like protein) indicate elicitation of SA and ethylene signaling (Choi and Hwang 2015). Root application of $B$. subtilis is associated with increasing ISR against TMV via activation of Coil, NPRI, $P R-1 a$, and $P R 1 b$, indicating activation of the SA signaling pathway (Wang et al. 2009). Over the past two decades, defense signaling in pepper plants has been elucidated (Choi and Hwang 2015). Interestingly, CaPR4, CaPR5, and CaPR10 expression in pepper plants is induced during resistance responses to diverse viruses, including TMV and CMV (Park et al. 2004). The defense priming of CaPR4, CaPR5, and CaPR10 by foliar application of strain 5B6 revealed in the current study appears to trigger a broad spectrum of resistance responses (Fig. 5), which has not previously been observed. The exact molecular mechanism should be elucidated in the near future.

In addition to the beneficial effects of 5B6 against plant disease, no reduction in fruit yield was detected in pepper plants treated with 5B6. Furthermore, vegetative growth (as indicated by shoot height) did not differ between 5B6-treated and water-treated plants (Table 1). Conversely, plants treated with $1 \mathrm{mM}$ BTH suffered a small reduction in shoot length and a large reduction in fruit yield. Overall, this is the first report to demonstrate that the leaf-colonizing bacilli protect pepper plants against viral diseases in the field. Further experiments are required to evaluate the efficacy of bacterial determinants related to elicitation of ISR by strain 5B6.

\section{Acknowledgments}

Financial support was obtained from the Industrial Source Technology Development Program of the Ministry of Knowledge Economy (10044909) of Korea, the Next-Generation BioGreen 21 Program (SSAC grant number PJ01111803), Rural Development Administration, South Korea; and the KRIBB Initiative Program, South Korea.

\section{Literature Cited}

Agrios, G. N. 2005. Plant Pathology. Academic Press, New York.

Bergstrom, G. C., Johnson, M. C., and Kuc, J. 1982. Effects of local infection of cucumber by Colletotrichum lagenarium, Pseudomonas lachrymans, or tobacco necrosis virus on systemic resistance to cucumber mosaic virus. Phytopathology 72:922-926.

Choi, H. K., Song, G. C., Yi, H. S., and Ryu, C. M. 2014. Field evaluation of the bacterial volatile derivative 3-pentanol in priming for induced resistance in pepper. J. Chem. Ecol. 40:882-892.

Choi, H. W., and Hwang, B. K. 2015. Molecular and cellular control of cell death and defense signaling in pepper. Planta 241:1-27.

Chung, J. H., and Ryu, C. M. 2016. Disease management of road trees and peppers by foliar application of Bacillus spp. Res. Plant Dis. In press.

Dekkers, L. C., Mulders, I. H. M., Phoelich, C. C., Chin-a-Woeng, T. F. C. Wijfjes, A. H. M., and Lugtenberg, B. J. J. 2000. The sss colonization gene of the tomato-Fusarium oxysporum f. sp. radicis-lycopersici biocontrol strain Pseudomonas fluorescens WCS365 can improve root colonization of other wild-type Pseudomonas spp. bacteria. Mol. Plant-Microbe Interact. 13: $1177-1183$. 
Dekkers, L. C., Phoelich, C. C., van der Fits, L., and Lugtenberg, B. J. J. 1998. A site-specific recombinase is required for competitive root colonization by Pseudomonas fluorescens WCS365. Proc. Natl. Acad. Sci. USA 95:7051-7056.

De Meyer, G., Audenaert, K., and Hofte, M. 1999. Pseudomonas aeruginosa 7NSK2 induced systemic resistance in tobacco depends on in planta salicylic acid but is not associated with PR1a expression. Eur. J. Plant Pathol. 105: 513-517.

Dietel, K., Beator, B., Budiharjo, A., Fan, B., and Borriss, R. 2013. Bacterial traits involved in colonization of Arabidopsis thaliana roots by Bacillus amyloliquefaciens FZB42. Plant Pathol. J. 29:59-66.

Eşitken, A., Karlidağ, H., Ercişli, S., and Şahin, F. 2002. Effects of foliar application of Bacillus subtilis Osu-142 on the yield, growth and control of shot-hole disease (Coryneum blight) of apricot. Gartenbauwissenschaft 67: 139-142.

Heil, M., and Baldwin, I. 2002. Fitness costs of induced resistance: Emerging experimental support for a slippery concept. Trends Plant Sci. 7:61-67.

Kang, S. H., Cho, H. S., Cheong, H., Ryu, C. M., Kim, J. F., and Park, S. H. 2007. Two bacterial endophytes eliciting both plant growth promotion and plant defense on pepper (Capsicum annuum L.). J. Microbiol. Biotechnol. 17:96-103.

Kerff, F., Amoroso, A., Herman, R., Sauvage, E., Petrella, S., Filée, P., Charlier, P., Joris, B., Tabuchi, A., Nikolaidis, N., and Cosgrove, D. J. 2008. Crystal structure and activity of Bacillus subtilis YoaJ (EXLX1), a bacterial expansin that promotes root colonization. Proc. Natl. Acad. Sci. USA 105: 16876-16881.

Kessmann, H., Staub, T., Hofmann, C., Maetzke, T., Herzog, J., Ward, E., Uknes, S., and Ryals, J. 1994. Induction of systemic acquired disease resistance in plants by chemicals. Annu. Rev. Phytopathol. 32:439-459.

Kim, B. K., Chung, J.-H., Kim, S.-Y., Jeong, H., Kang, S. G., Kwon, S.-K., Lee, C. H., Song, J. Y., Yu, D. S., Ryu, C.-M., and Kim, J. F. 2012. Genome sequence of the leaf-colonizing bacterium Bacillus sp. strain 5B6, isolated from a cherry tree. J. Bacteriol. 194:3758-3759.

Kishore, G. K., and Pande, S. 2007. Chitin-supplemented foliar application of chitinolytic Bacillus cereus reduces severity of Botrytis gray mold disease in chickpea under controlled conditions. Lett. Appl. Microbiol. 44:98-105.

Kloepper, J. W., Reddy, M. S., Rodríguez-Kabana, R., Kenney, D. S., KokalisBurelle, N., and Martinez-Ochoa, N. 2004. Application for rhizobacteria in transplant production and yield enhancement. Acta Hortic. 631:219-229.

Lamberth, C., Jeanmart, S., Luksch, T., and Plant, A. 2013. Current challenges and trends in the discovery of agrochemicals. Science 341:742-746.

Lee, B., Lee, S., and Ryu, C. M. 2012. Foliar aphid feeding recruits rhizosphere bacteria and primes plant immunity against pathogenic and non-pathogenic bacteria in pepper. Ann. Bot. (Lond.) 110:281-290.

Li, H., Zhao, J., Feng, H., Huang, L., and Kang, Z. 2013. Biological control of wheat stripe rust by an endophytic Bacillus subtilis strain E1R-j in greenhouse and field trials. Crop Prot. 43:201-206.

Lugtenberg, B. J., Dekkers, L., and Bloemberg, G. V. 2001. Molecular determinants of rhizosphere colonization by Pseudomonas. Annu. Rev. Phytopathol. 39: 461-490.

Mandadi, K. K., and Scholthof, K. B. 2013. Plant immune responses against viruses: How does a virus cause disease? Plant Cell 25:1489-1505.

Mann, E. W. 1969. Inhibition of tobacco mosaic virus by a bacterial extract. Phytopathology 59:658-662.

Maurhofer, M., Hase, C., Meuwly, P., Metraux, J. P., and Defago, G. 1994. Induction of systemic resistance of tobacco to tobacco necrosis virus by the root-colonizing Pseudomonas fluorescens strain CHA0: Influence of the gacA gene and of pyoverdine production. Phytopathology 84:139-146.

Mavrodi, O. V., Mavrodi, D. V., Weller, D. M., and Thomashow, L. S. 2006. Role of ptsP, orfT, and sss recombinase genes in root colonization by Pseudomonas fluorescens Q8r1-96. Appl. Environ. Microbiol. 72:7111-7122.

Mercier, J., and Lindow, S. E. 2001. Field performance of antagonistic bacteria identified in a novel assay for biological control of fireblight. Biol. Control 22:66-71.

Milgroom, M., and Cortesi, P. 2004. Biological control of chestnut blight with hypoviulence: A critical review. Annu. Rev. Phytopathol. 42:311-338.

Murphy, A. M., Chivasa, S., Singh, D. P., and Carr, J. P. 1999. Salicylic acidinduced resistance to viruses and other pathogens: A parting of the ways? Trends Plant Sci. 4:155-160.
Murphy, J. F. 2006. Applied aspects of induced resistance to plant virus infection. Pages 1-11 in: Natural Resistance Mechanisms of Plants to Viruses. G. Loebenstein and J. P. Carr, eds. Springer, The Netherlands.

Murphy, J. F., Reddy, M. S., Ryu, C. M., Kloepper, J. W., and Li, R. 2003. Rhizobacteria mediated growth promotion of tomato leads to protection against Cucumber mosaic virus. Phytopathology 93:1301-1307.

Murphy, J. F., Zehnder, G. W., Schuster, D. J., Sikora, E. J., Polston, J. E., and Kloepper, J. W. 2000. Plant growth-promoting rhizobacterial mediated protection in tomato against Tomato mottle virus. Plant Dis. 84:779-784.

Nihorimbere, V., Cawoy, H., Seyer, A., Brunelle, A., Thonart, P., and Ongena, M 2012. Impact of rhizosphere factors on cyclic lipopeptide signature from the plant beneficial strain Bacillus amyloliquefaciens S499. FEMS Microbiol. Ecol. 79:176-191

Park, C. J., Kim, K. J., Shin, R., Park, J. M., Shin, Y. C., and Paek, K. H. 2004. Pathogenesis-related protein 10 isolated from hot pepper functions as a ribonuclease in an antiviral pathway. Plant J. 37:186-198.

Pennazio, S., and Roggero, P. 1998. Systemic acquired resistance against plant virus infections: A reality? J. Plant Pathol. 80:179-186.

Perring, T. M., Gruenhagen, N. N., and Farrar, C. A. 1999. Management of plant viral diseases through chemical control of insect vectors. Annu. Rev. Entomol. 44:457-481.

Raupach, G. S., and Kloepper, J. W. 1998. Mixtures of plant growth-promoting rhizobacteria enhance biological control of multiple cucumber pathogens. Phytopathology 88:1158-1164.

Raupach, G. S., Liu, L., Murphy, J. F., Tuzun, S., and Kloepper, J. W. 1996. Induced systemic resistance against cucumber mosaic cucumovirus using plant growth promoting rhizobacteria (PGPR). Plant Dis. 80:891-894.

Ross, A. F. 1961. Systemic acquired resistance induced by localized virus infections in plants. Virology 14:340-358.

Scholthof, K. B. G., Scholthof, H. B., and Jackson, A. O. 1993. Control of plant virus disease by pathogen-derived resistance in transgenic plant. Plant Physiol. 102:7-12.

Singh, D. P., Moore, C. A., Gilliland, A., and Carr, J. P. 2004. Activation of multiple antiviral defence mechanisms by salicylic acid. Mol. Plant Pathol. 5: 57-63.

Song, G. C., Choi, H. K., and Ryu, C. M. 2013. The folate precursor paraaminobenzoic acid elicits induced resistance against Cucumber mosaic virus and Xanthomonas axonopodis. Ann. Bot. (Lond.) 111:925-934.

Tally, A., Oostensdorp, M., Lawton, K., Staub, T., and Bassi, B. 1999. Commercia development of elicitors of induced resistance to pathogens. Pages 357-369 in: Induced Plant Defenses Against Pathogens And Herbivores. A. Agrawal, S. Tuzun, and E. Bent, eds. American Phytopathological Society, St. Paul, MN

Timmusk, S., Kim, S. B., Nevo, E., Abd, E., Daim, I., Ek, B., Bergquist, J., and Behers, L. 2015. Sfp-type PPTase inactivation promotes bacterial biofilm formation and ability to enhance wheat drought tolerance. Front. Microbiol. 6:00387.

van Loon, L. C., Bakker, P. A. H. M., and Pieterse, C. M. J. 1998. Systemic resistance induced by rhizosphere bacteria. Annu. Rev. Phytopathol. 36:453-483.

Wang, S., Wu, H., Qiao, J., Ma, L., Liu, J., Xia, Y., and Gao, X. 2009. Molecular mechanism of plant growth promotion and induced systemic resistance to tobacco mosaic virus by Bacillus spp. J. Microbiol. Biotechnol. 19:1250-1258.

Weng, J., Wang, Y., Li, J., Shen, Q., and Zhang, R. 2013. Enhanced root colonization and biocontrol activity of Bacillus amyloliquefaciens SQR9 by $a b r B$ gene disruption. Appl. Microbiol. Biotechnol. 97:8823-8830.

Yang, J. W., Yi, H. S., Kim, H., Lee, B., Lee, S., Ghim, S. Y., and Ryu, C. M. 2011 Whitefly infestation of pepper plants elicits defence responses against bacterial pathogens in leaves and roots and changes the below-ground microflora. J. Ecol. 99:46-56.

Yarwood, C. E. 1960. Localized acquired resistance to tobacco mosaic virus Phytopathology 50:741-744.

Yi, H. S., Yang, J. W., Choi, H. K., Ghim, S. Y., and Ryu, C. M. 2012 Benzothiadiazole-elicited defense priming and systemic acquired resistance against bacterial and viral pathogens of pepper under field conditions. Plant Biotechnol. Rep. 6:373-380.

Zehnder, G. W., Yao, C., Murphy, J. F., Sikora, E. J., and Kloepper, J. W. 2000 Induction of resistance in tomato against cucumber mosaic cucumovirus by plant growth-promoting rhizobacteria. BioControl 45:127-137. 